أثر إعادة توزيع زراعة أصناف الذرة الثامية على انتاجيتها

\author{
علاء الدين سعيد الشبراوى
}

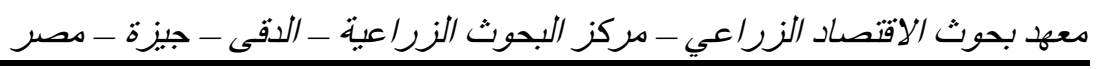

المستخط

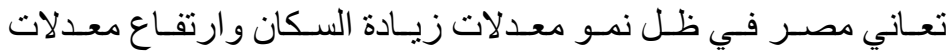

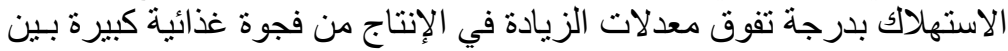

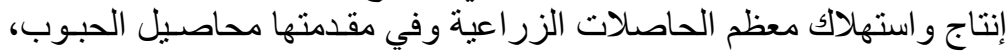

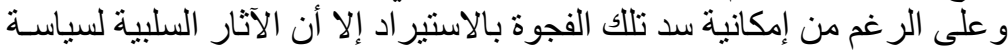

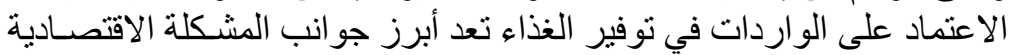

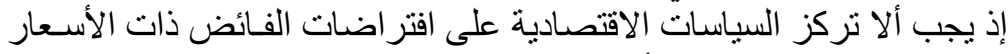

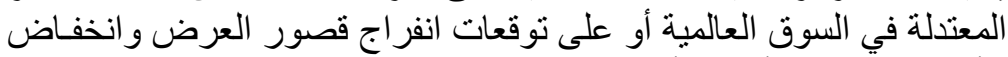

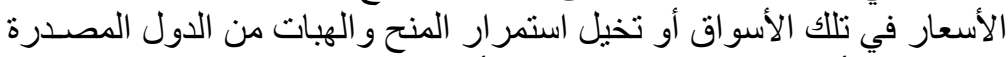

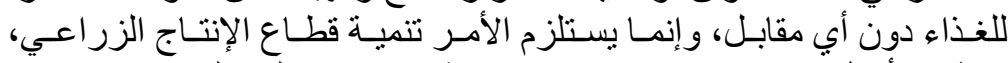

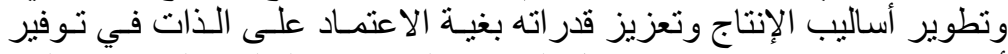

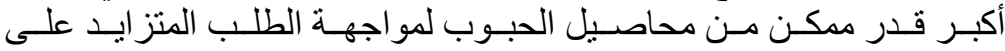

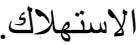

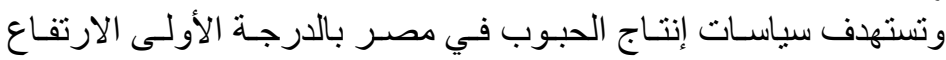

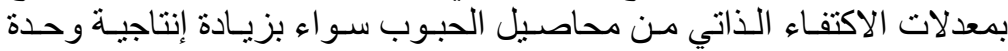

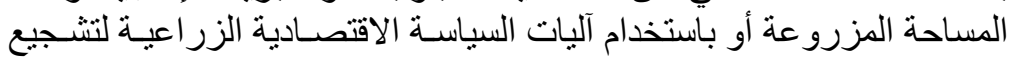

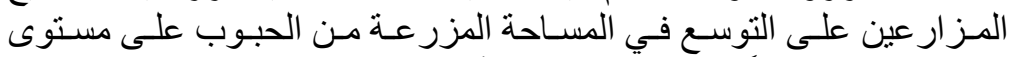

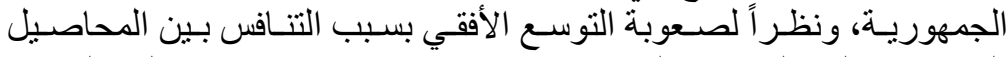

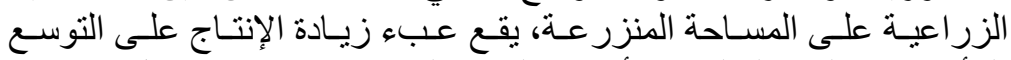

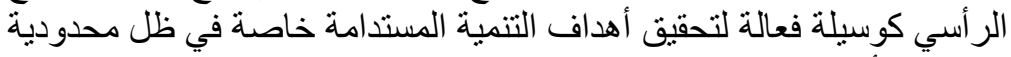

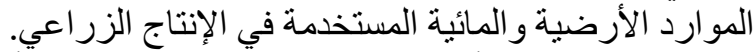

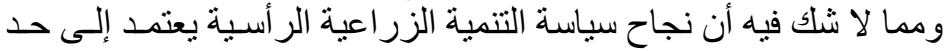

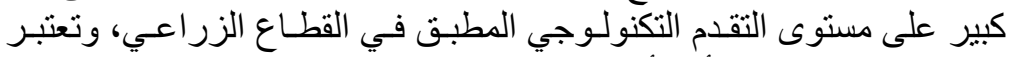

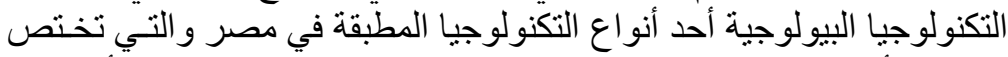

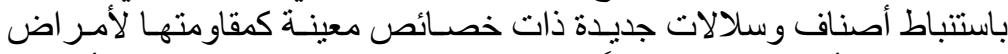

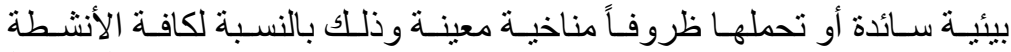

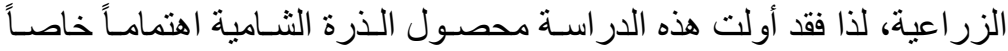

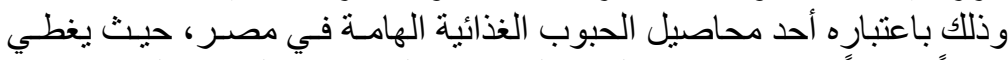

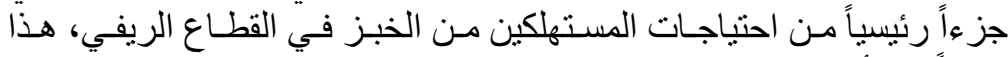

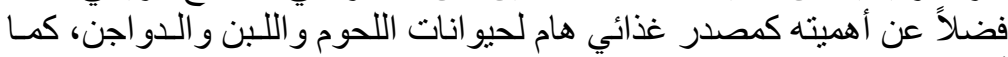

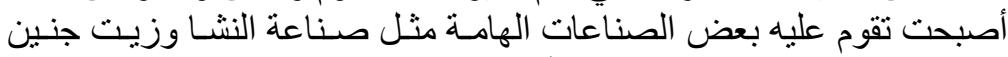

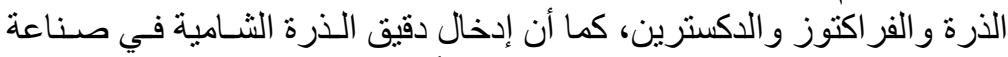

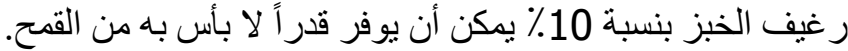

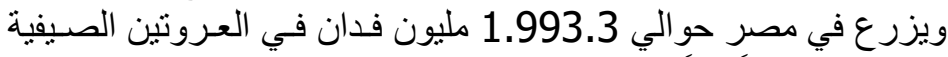

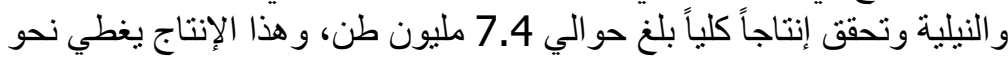

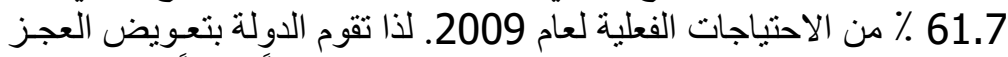

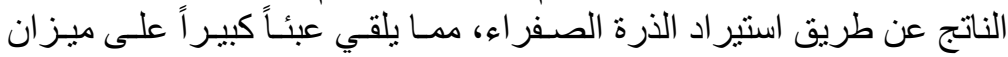

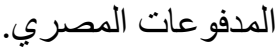

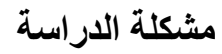

تشـير التقدير ات الفعليـة لإنتاجيـة أصـناف الذرة الثـامية المزرو عـة على مسـتوى المنـاطق

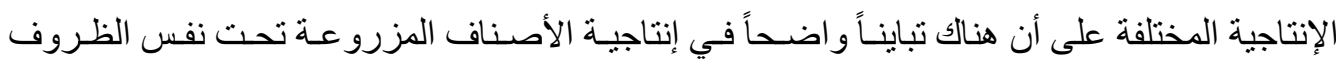




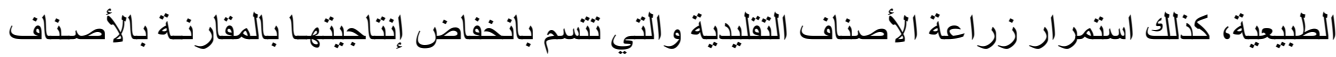

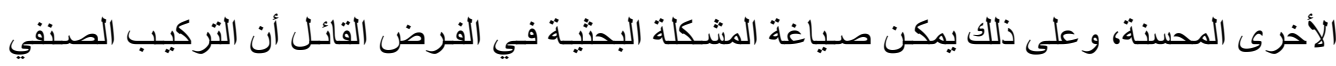

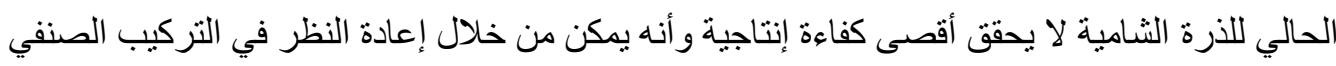

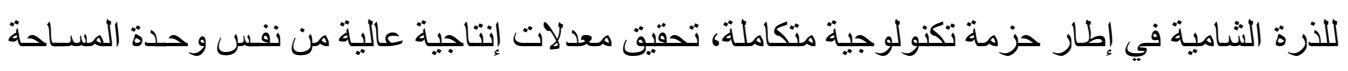

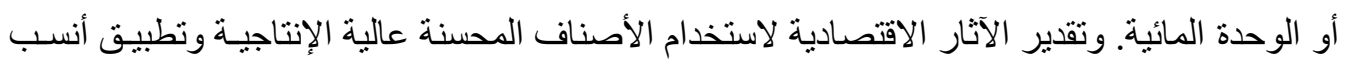

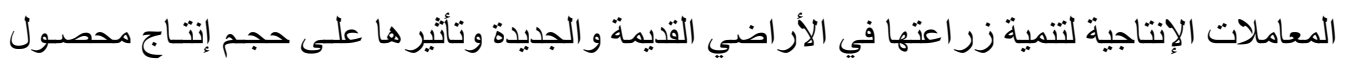

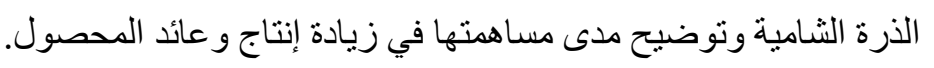

\section{الههف من الدراسة}

تهدف الدراسة إلى تحديد الآثار الاقتصادية لمدى مساهمة الأصناف المحسنة في زيـادة إنتاج

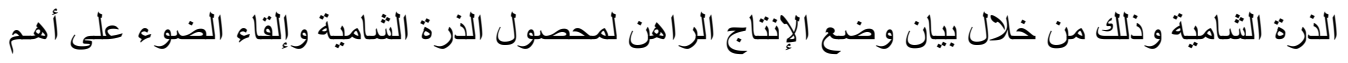

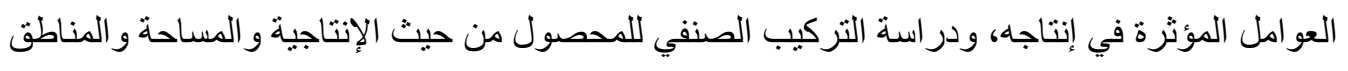

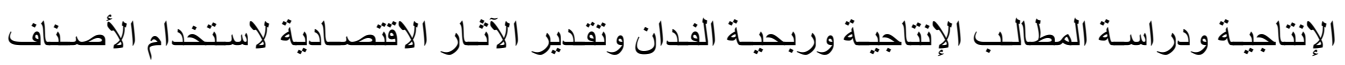

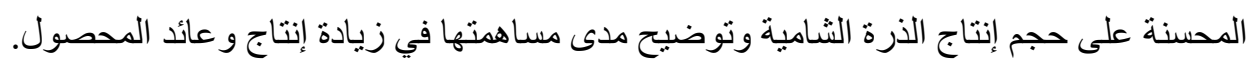
الطريقة البحثية ومصادر البيانات

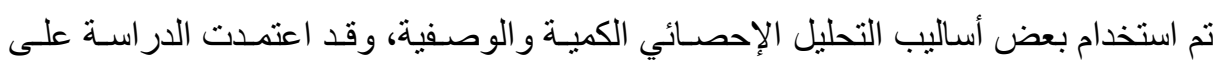

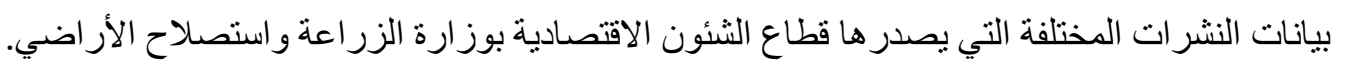




\section{نتائج الاراسة}

الوضع الانتاجى الراهن لمحصول الأرة الثنامية

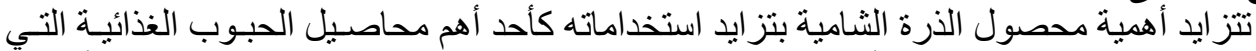

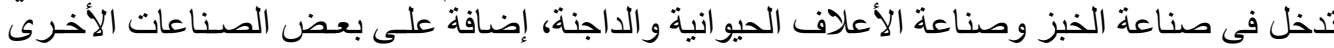

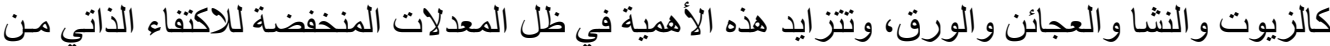

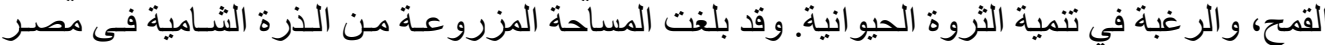

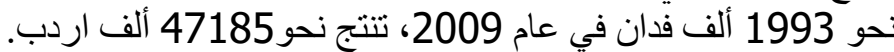

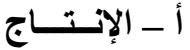

يشير الجدول رقم ( 1 ) إلى معادلات الانحدار الخطى لتطور أهـ المؤشـرات الإنتاجيـة لمحصـول

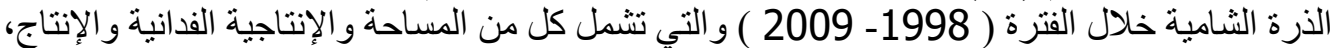

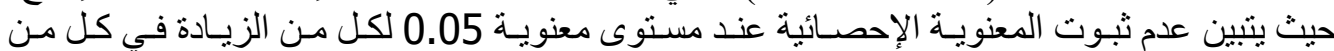
المساحة و الإنتاجية الفدانية واجمالى الإنتاج من الذرة الثنامية في الوجه البحنية البحري.

وبالنسبة لأهم المؤشر ات الإنتاجية لمحصول الذرة الثنامية في منطقة مصـر الوسطى يتضـح

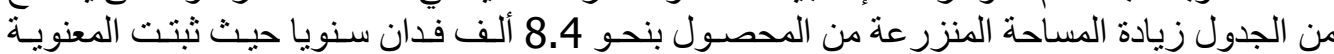

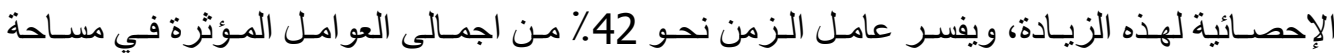

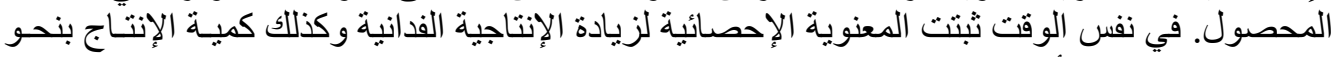

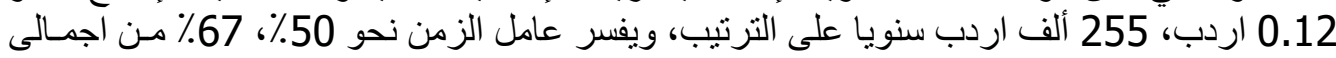

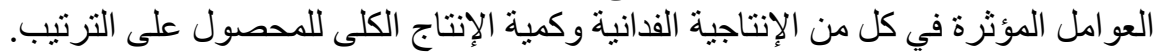

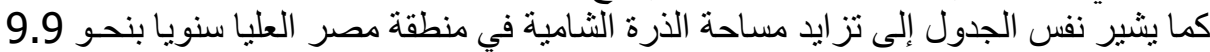

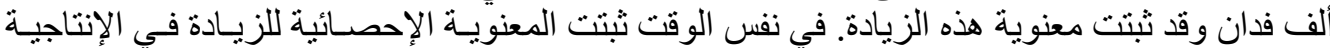

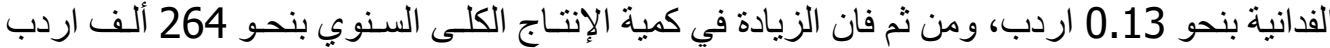

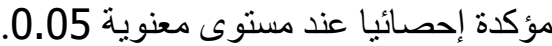

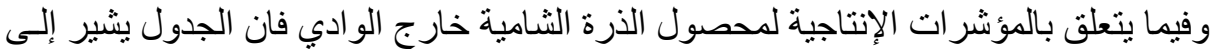

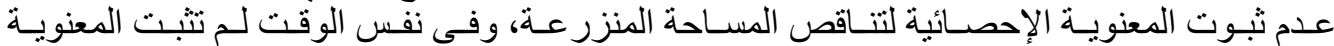

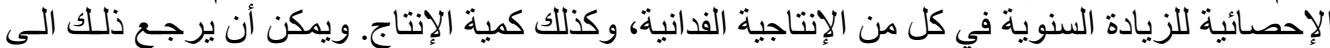

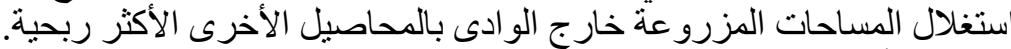

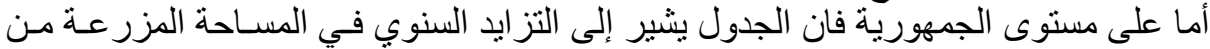

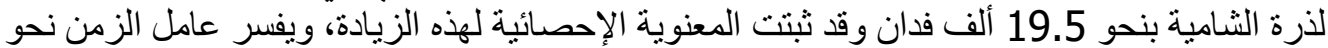

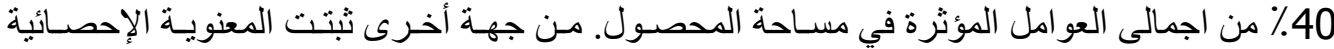

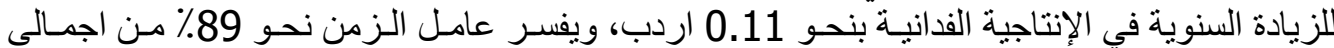

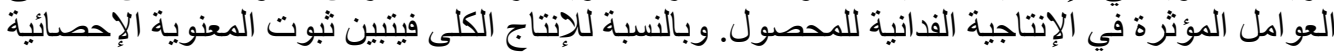

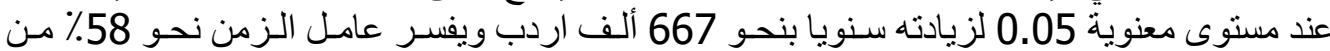
اجمالى العوامل المؤثرة في كمية الإنتاج الكلى للمحصول.

جدول (1) معادلات الاتجاه الزمني العام لتطور أهم المؤشرات الإنتاجية لمحصول

الأزرة الثامية خلال الفترة (1998- 2009)

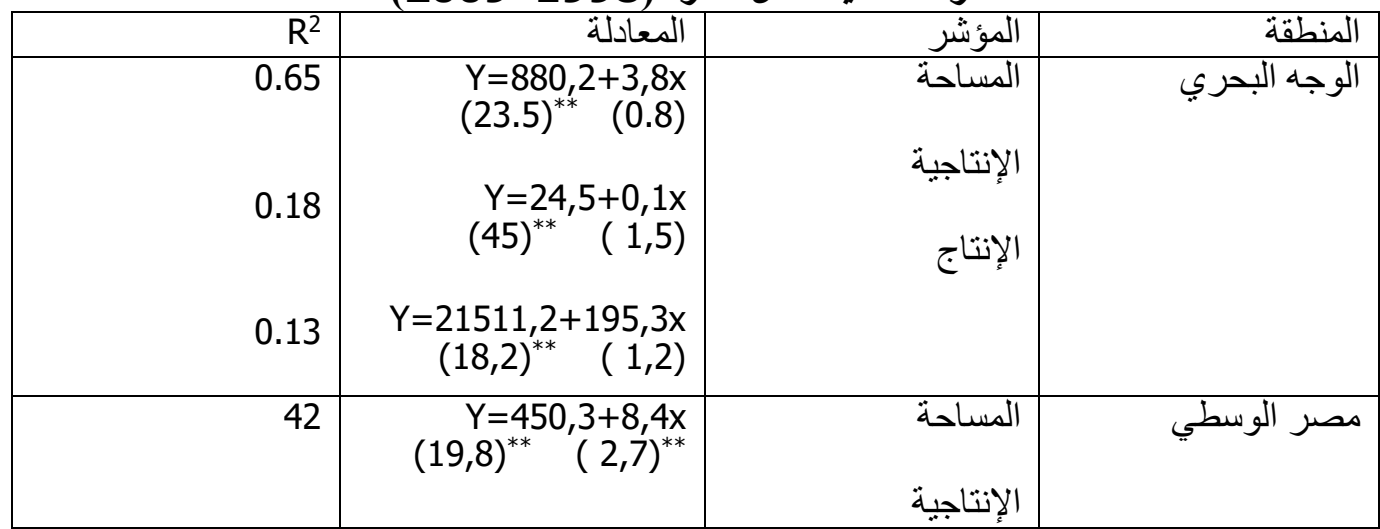




\begin{tabular}{|c|c|c|c|}
\hline 0.67 & $\begin{array}{r}\mathrm{Y}=22,8+0,12 \mathrm{x} \\
(52,7)^{* *}(2,1)^{*} \\
\\
\mathrm{Y}=10246+255 \mathrm{x} \\
(24,8)^{* *}(4,5)^{* *}\end{array}$ & الإنتاج & \\
\hline $\begin{array}{l}0.94 \\
0,60 \\
0.93\end{array}$ & $\begin{array}{r}\mathrm{Y}=223,1+9,9 x \\
(40,3)^{* *}(13,1)^{* *} \\
\mathrm{Y}=22,2+0,13 \mathrm{x} \\
(47,1)^{* *}(2,1)^{*} \\
\mathrm{Y}=4912+264 \mathrm{x} \\
(29,7)^{* *}(11,8)^{* *}\end{array}$ & الإلإنتاجية & مصر العليا \\
\hline $\begin{array}{l}0.22 \\
0.32 \\
0.47\end{array}$ & 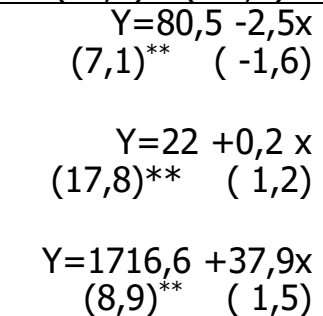 & الإلإنتاجية & خارج الو ادي \\
\hline $\begin{array}{l}0.40 \\
0.89 \\
0.58\end{array}$ & $\begin{array}{r}\mathrm{Y}=1634,2+19,5 x \\
(29,3)^{* *} \quad(2,6)^{* *} \\
\\
\mathrm{Y}=23,6+0,11 \mathrm{x} \\
(57,5)^{* *} \quad(2,01)^{*} \\
\mathrm{Y}=38577+667 x \\
(29,4)^{* *}(3,7)^{* *}\end{array}$ & الإلإنتاجية & اجمالى الجمهورية \\
\hline & سىى، قطاع الثئون الاقتصادية، & 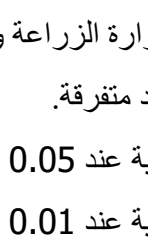 & نشرة الاقتصاد الزر اعيت من بيان \\
\hline
\end{tabular}




\section{التوزيع المكاني لإنتاج الذرة الثامية محلياً:}

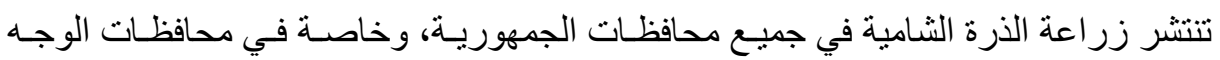

البحري، ويقل انتشار ها بصفة عامة بالاتجاه إلى محافظات مصر العليا، حيث يتضح من جدول رقم (2) أن الرقعة المزروعة بالذرة الثشامية في كل من: الوجه البحري ومصر الوسطى ومصر العليا تمثل نحو

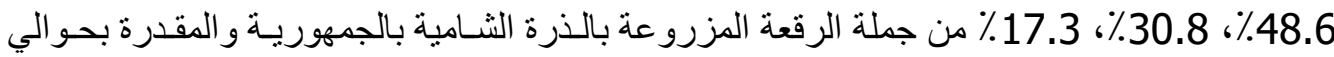

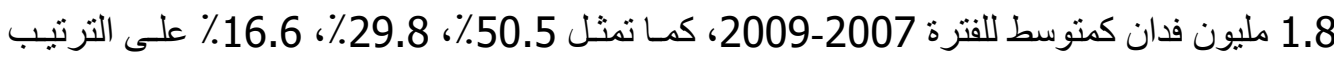
من كمية الناتج و المقدر بحو الي 6.2 مليون طن وذللك كمتوسط للفترة السـابق ذكر هـا. وتعد محافظـات المنيا و المنوفية و الثرقية وبني سويف و البحيرة أهم المحافظات المنتجة للذرة الثنامية بصفة عامة، حيث

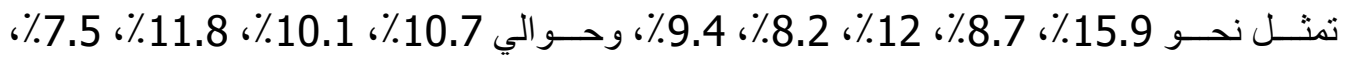

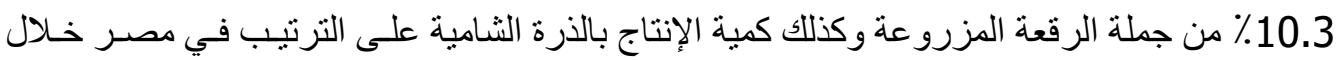
متوسط الفترة 2007-2009 هذا وتجدر الإشارة إلى زيادة تركز زر اعة الذرة الثامية مع الاتجاه نحو

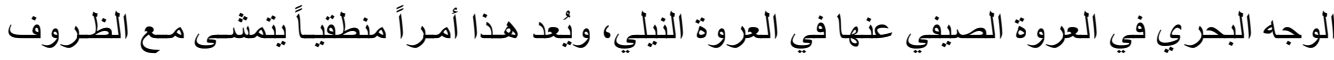

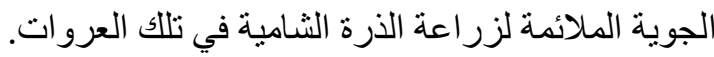
هذا وتجدر الإشارة إلى تفاوت الإنتاجية الفدانية للذرة الثامية وفقاً للعروة وللمنطقة المزروعـة

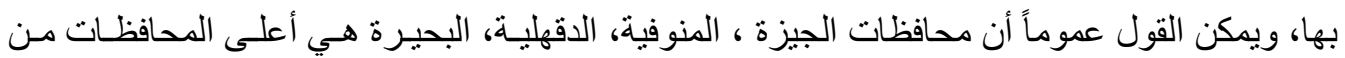

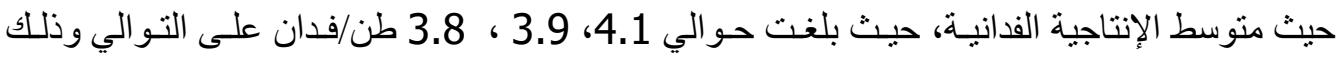

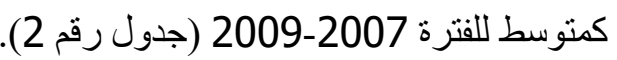
جدول رقم (2): الأهمية النسبية لأهم المحافظات المنتجة للأرة الثامية في جمهورية مصر العربية

\section{خلال متوسط الفترة 2007-2009.}

\begin{tabular}{|c|c|c|c|c|c|c|}
\hline \multicolumn{2}{|c|}{ الإنتاج } & \multicolumn{2}{|c|}{ لإلساجية } & \multicolumn{2}{|c|}{ المساحة } & \multirow{2}{*}{ البحافظة } \\
\hline$\%$ & مليون طن & 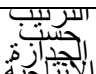 & ط/4داט & $\%$ & ألف فدان & \\
\hline 10.7 & 663.2 & 11 & 2.3 & 15.9 & 288.2 & المنيا \\
\hline 10.07 & 621.8 & 2 & 3.9 & 8.7 & 158.9 & المنوفية \\
\hline 11.8 & 729.1 & 7 & 3.3 & 12.0 & 217.9 & 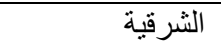 \\
\hline 7.5 & 465.6 & 10 & 3.1 & 8.2 & 148.9 & بني سويف \\
\hline 10.3 & 638.1 & 4 & 3.8 & 9.4 & 169.9 & البحيرة \\
\hline 4.1 & 251.9 & 2 & 3.9 & 3.5 & 63.7 & 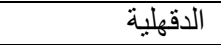 \\
\hline 2.3 & 140.6 & 1 & 4.1 & 2.4 & 43.4 & الجيزة \\
\hline 2.9 & 179.8 & 5 & 3.5 & 2.8 & 50.9 & كفر الثيخ \\
\hline 50.5 & 311.9 & 5 & 3.5 & 48.6 & 881.3 & وجه بحري \\
\hline 29.8 & 1838.4 & 7 & 3.3 & 30.8 & 559.2 & مصر الوسطى \\
\hline 16.6 & 1025.6 & 7 & 3.3 & 17.3 & 313.9 & مصر العليا \\
\hline 100 & 6174.2 & - & 3.4 & 100 & 1814.2 & إجمالي الجمهورية \\
\hline
\end{tabular}

\section{3- قياس أثر المساحة والإنتاجية على إنتاج الذرة الثامية في مصر:}

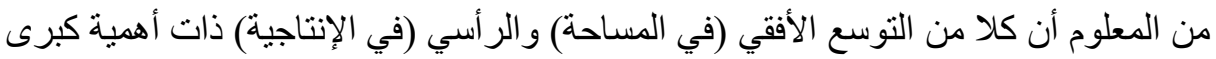

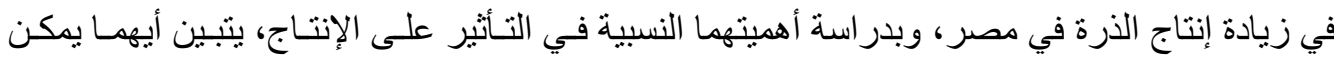

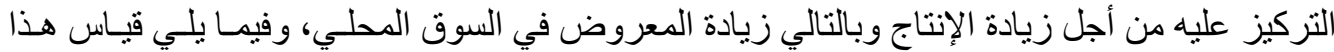

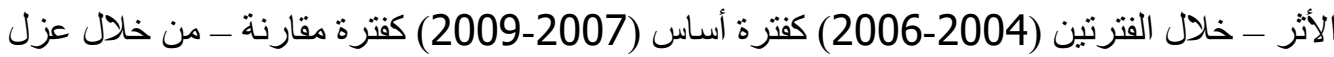
تأثير المساحة والإنتاجية على كمية الإنتاج. 
وباستعر اض نتائج جدول رقم (3) ينضـح زيـادة إجمـالي إنتـاج الذرة الثـامية خـلال فترة المقارنــة

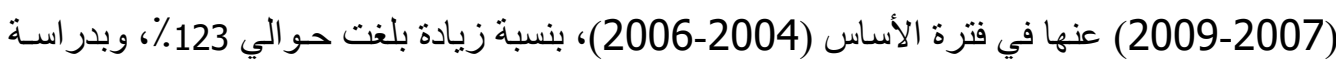

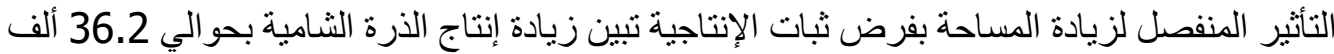

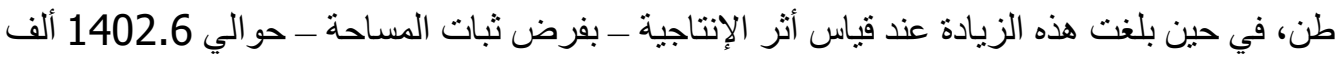

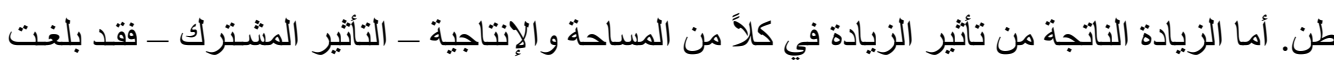
حو الي 1439.1 ألف طن.

هذاو عند تحديد الأهمية النسبية لتأثير كلا مـن المسـاحة و الإنتاجيـة على إنتـاج الذرة الثـامية

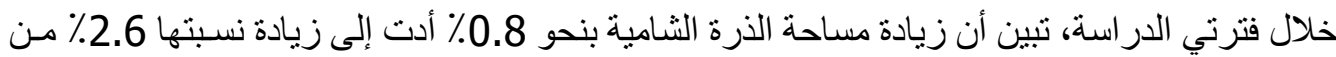

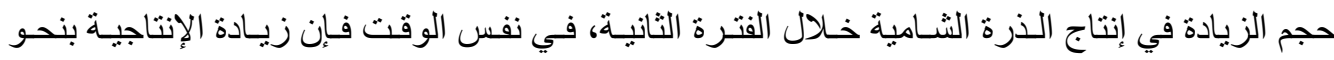

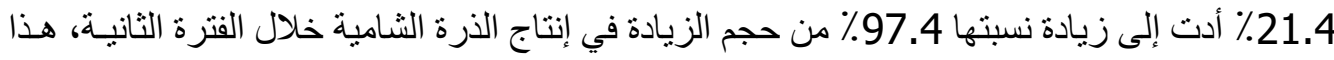

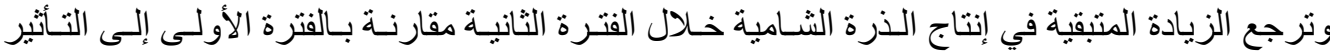

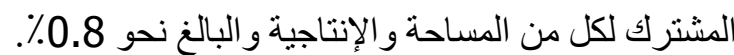

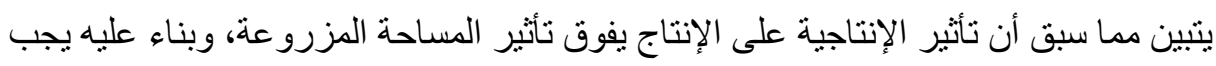

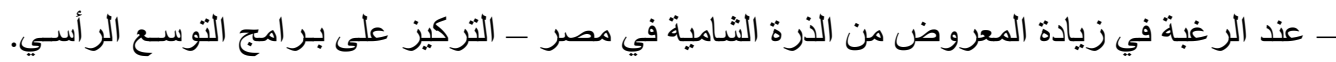

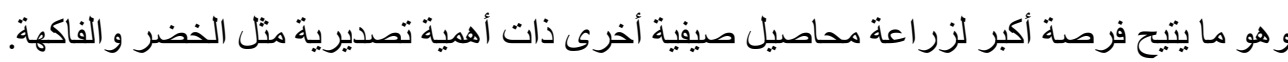
جدول رقم (3) أثر المساحة والإنتاجية على التغير في إنتاج الذرة الثامية فئة

في مصر خلال الفترة (3) (2009/2007-2006/2004)

\begin{tabular}{|c|c|c|c|c|c|c|c|}
\hline \multirow{2}{*}{ الأهمية النسبية } & \multicolumn{3}{|c|}{ الثأثر المطلق لتغير كلا من الكمية السعر بين فترتي } & \multicolumn{3}{|c|}{ متوسط فترني الدر اسة } & \multirow{2}{*}{ البيان } \\
\hline & التأثير المتتابع & الكل الثنغيرين المشترك & التأثير المنفصل متغير & رقم القياسي 2 × 100 × & $\begin{array}{c}2009-2007 \\
(2)\end{array}$ & $\begin{array}{c}2006-2004 \\
\text { (1) }\end{array}$ & \\
\hline 2.6 & & & 36.2 & 100.8 & 1814.2 & 1799.3 & 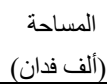 \\
\hline 97.4 & & & 1402.9 & 121.4 & 3.4 & 2.8 & الإنتاجية \\
\hline 100.0 & 1448.2 & 9.1 & 1439.1 & 123.2 & 6174.2 & 5013 & (ألف طن) \\
\hline
\end{tabular}

المصدر: جمعت وحسبت من بيانات وز ارة الزر اعة و استصلاح الار اضى، قطساع الثـئون الاقتصـادية، نشرة الاقتصاد الزر اعي، أعداد متفرقة. الفروق بين إنتاجية أهم الأصناف المختلفة للأرة الثامية: تم استخدام تحليل التباين لتحديد معنوية الفروق بين إنتاجية أهم الأصناف المزرعـة مـن الذرة

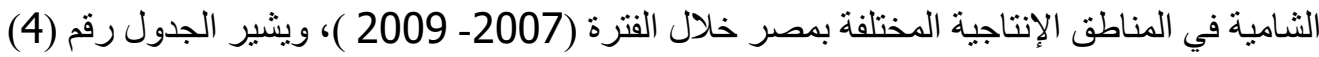

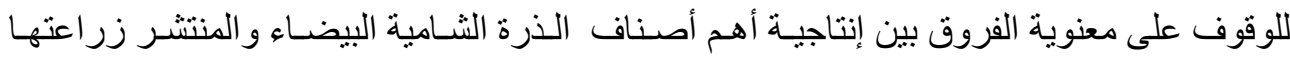

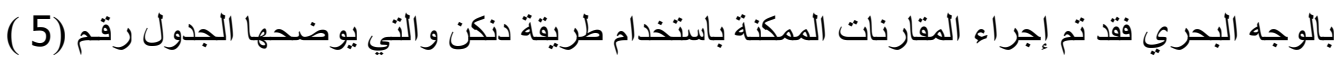
حيث يتبين وجود فرق معنوي بين صنف هجين فردى وطنية 4 وهو اقل الأصناف مـن حيث الإنتاجيـة

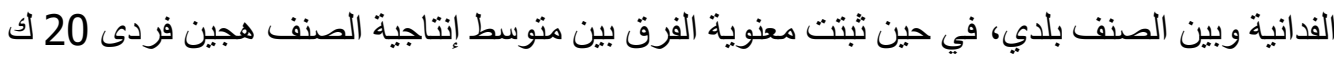

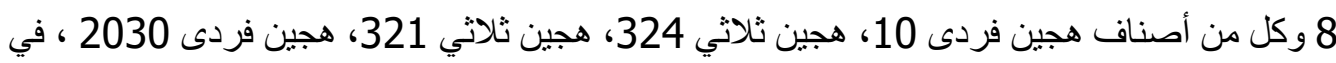

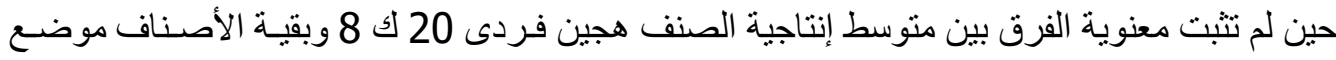

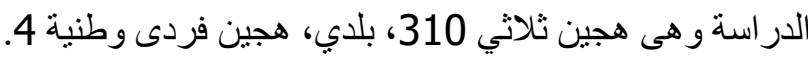

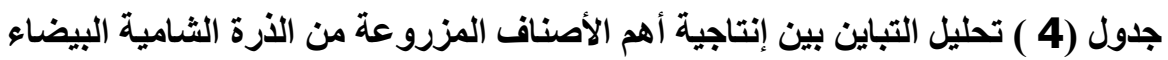


الصيفي بالمناطق الإنتاجية المختلفة خلال الفترة ( 2007- 2009 )

\begin{tabular}{|c|c|c|c|c|c|}
\hline ف المحسوبة & منوسط مجموع & مجموع مربعات & درجات الحرية & مصدر التباين & المناطق \\
\hline 9.1 & $\begin{array}{l}7.62 \\
0.84\end{array}$ & $\begin{array}{l}53.4 \\
13.4 \\
66.8 \\
\end{array}$ & $\begin{array}{c}7 \\
16 \\
23\end{array}$ & داخل الأصناف الأصناف & الوجه البحري \\
\hline 1.01 & $\begin{array}{c}2.3 \\
2.28\end{array}$ & $\begin{array}{l}16.2 \\
36.5 \\
52.7\end{array}$ & $\begin{array}{c}7 \\
16 \\
23\end{array}$ & 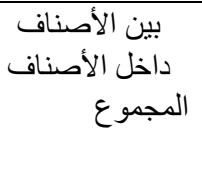 & مصر الوسطي \\
\hline 7.1 & $\begin{array}{c}4.5 \\
0.64\end{array}$ & $\begin{array}{c}31.7 \\
10.3 \\
42\end{array}$ & $\begin{array}{c}7 \\
16 \\
23\end{array}$ & بين الأصناف الأصناف & مصر العليا \\
\hline 10.22 & $\begin{array}{c}79.8 \\
7.8\end{array}$ & $\begin{array}{l}558.5 \\
124.9 \\
683.4 \\
\end{array}$ & $\begin{array}{c}7 \\
16 \\
23\end{array}$ & داخل الأصناف الأصناف & خارج الو ادي \\
\hline 14.2 & $\begin{array}{c}9.1 \\
0.64\end{array}$ & $\begin{array}{l}63.9 \\
10.3 \\
74.2\end{array}$ & $\begin{array}{c}7 \\
16 \\
23\end{array}$ & داخل الأصناف الأصناف & الجمهورية \\
\hline
\end{tabular}

الإقتصاد الزرأعى، اعداد متفرقة. 
جلول ( 5 ) نتائج تقدير معنوية الفروق بين إنتاجية أهم أصناف الذرة الثامية المزروعة في الوجه البحري خلال الفترة ( 2007 الفئ 2009 )

\begin{tabular}{|c|c|c|c|c|c|c|c|c|c|}
\hline ونجنيزئي & بلدي & ثلاثى هج $31{ }^{3}$ & فردىهجن & ثلاثى هج:32 & ثلاثى هج:32 & هج.فردى 10 & فردى هُخكت8 & & الصنف \\
\hline 22,13 & 23,05 & 24,53 & 25,21 & 25,46 & 25,84 & 26,22 & 26,71 & الإنتاجية & \\
\hline \multirow[t]{8}{*}{0,00} & 0,92 & 2,40 & $* 3,08$ & $* 3,33$ & $* 3,71$ & $* 4,09$ & $* 4,58$ & 22,13 & هج.فردنوطنية4 \\
\hline & 0,00 & 1,48 & 2,17 & 2,42 & $* 2,80$ & $* 3,17$ & $* 3,66$ & 23,05 & بلدي \\
\hline & & 0,00 & 0,69 & 0,94 & 1,32 & 1,69 & 2,18 & 24,53 & هج.ثلاثى310 \\
\hline & & & 0,00 & 0,25 & 0,63 & 1,00 & 1,49 & 25,21 & هج.فردى2030 \\
\hline & & & & 0,00 & 0,38 & 0,75 & 1,24 & 25,46 & هج. ثلاثى321 \\
\hline & & & & & 0,00 & 0,37 & 0,86 & 25,84 & هج. ثلاثى324 \\
\hline & & & & & & 0,00 & 0,49 & 26,22 & هج.فردى 10 \\
\hline & & & & & & & 0,00 & 26,71 & هج.فردى20ك8 \\
\hline
\end{tabular}

المصدر: حسبت من بيانات وز ارة الزر اعة واستصلاح الار اضى، قطاع الثئون الاقتصادية، نشرة الاقتصاد الزراعي، أعداد متفرقة.

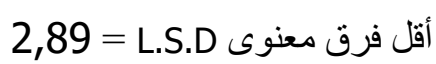


وفيما يتعلق بالفروق المعنوية بين إنتاجية أهم أصناف الذرة الثامية في مصر الوسطي يشير

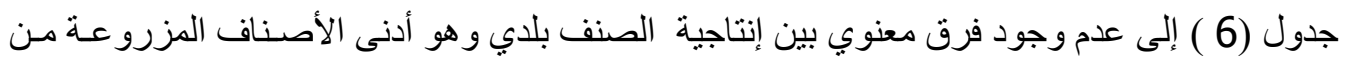

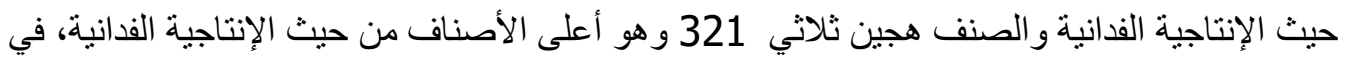

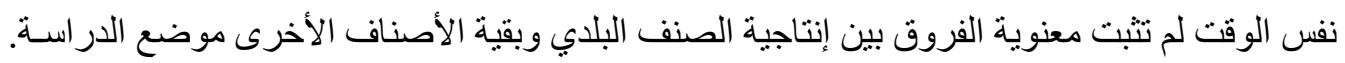

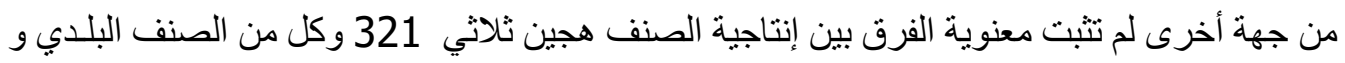

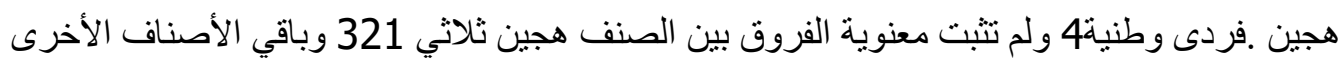
موضع الدراسة .

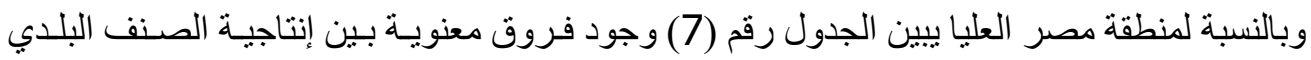

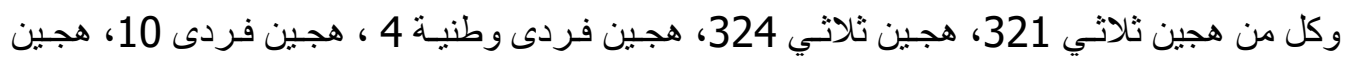

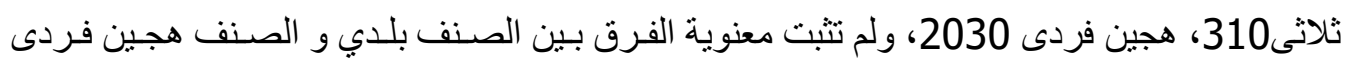

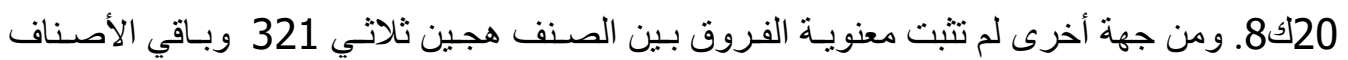
الأخرى موضع الدر اسة ما عدا الصنف لـألدي.

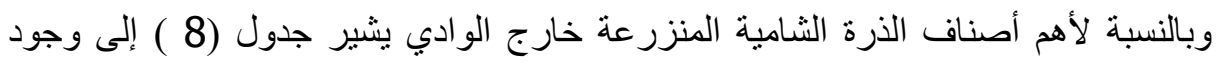

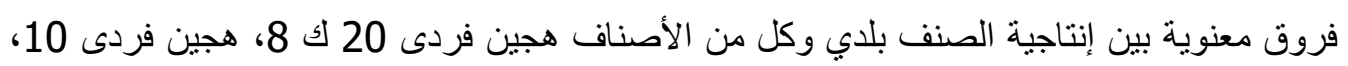

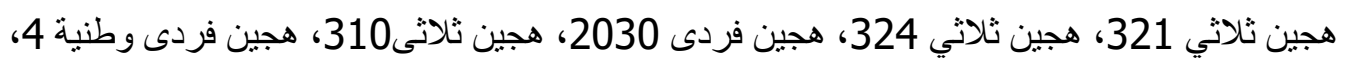

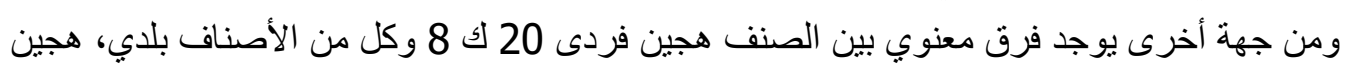

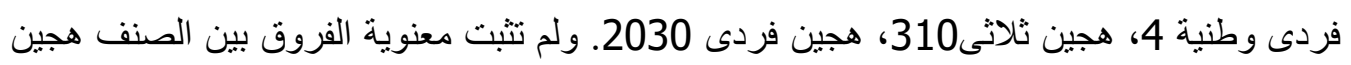

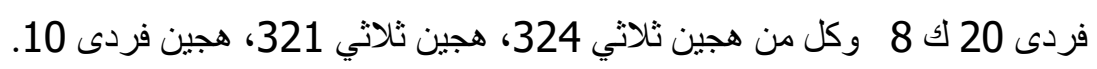

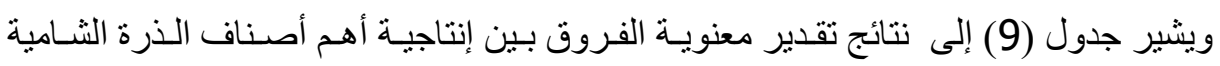

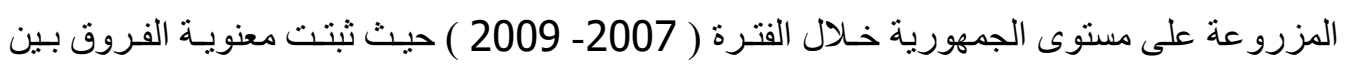

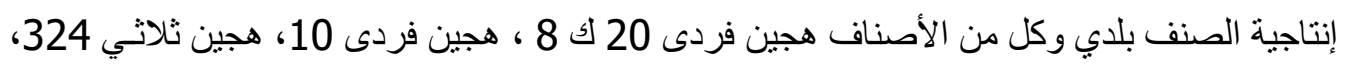
هجين ثلاثي 321، هجين فردى 2030 ، هجين ثناثى 310، هجين فردى وطنية 4.

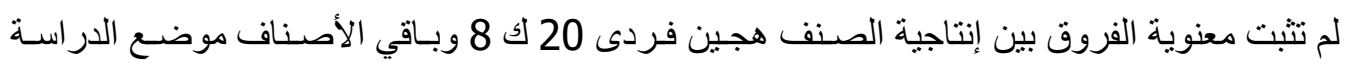
باستثناء الصنف بلدي.

مما سبق يتبين أن تطبيتق سياسـة إعـادة توزيـع الأصـناف على مستوى المنـاطق الجغر افيـة

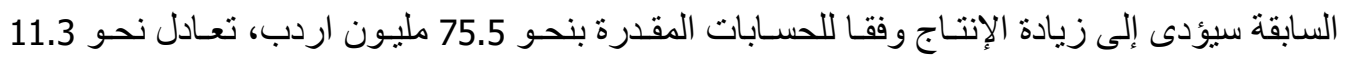

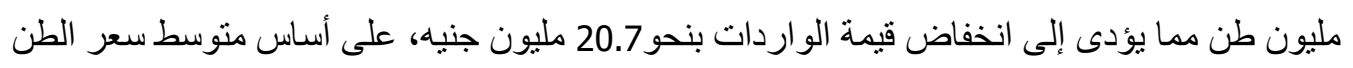
حو الي 1832 جنبه كمتوسط للفترة (2007-2009). 
جدول ( 6 ) نتائج تقدير معنوية الفروق بين إنتاجية أهم أصناف الذرة الثامية المزرعة في مصر الوسطى خلال الفترة ( 2007 (2009 2009 )

\begin{tabular}{|c|c|c|c|c|c|c|c|c|c|}
\hline بلدي & ونظنية & ثلاثىنجة 31 & هج. في 8 & هج. فردى & فردى هجن & ثلاثى هُ4: & ثلاثى هُ1ج. & & \multirow[t]{2}{*}{ الصنف } \\
\hline 22,29 & 22,38 & 22,86 & 23,56 & 23,57 & 23,83 & 23,86 & 24,86 & الانتوناحية & \\
\hline \multirow[t]{8}{*}{0,00} & 0,09 & 0,57 & 1,27 & 1,29 & 1,55 & 1,57 & 2,58 & 22,29 & بلدي \\
\hline & 0,00 & 0,48 & 1,18 & 1,19 & 1,45 & 1,48 & 2,48 & 22,38 & هج.فردونوطنيه4 \\
\hline & & 0,00 & 0,70 & 22,86 & 0,97 & 1,00 & 2,00 & 22,86 & هج. ثنلاتى310 \\
\hline & & & 0,00 & 0,02 & 0,28 & 0,30 & 1,31 & 23,56 & هج.فردى20ك8 \\
\hline & & & & 0,00 & 0,26 & 0,28 & 1,29 & 23,57 & هج.فردى 10 \\
\hline & & & & & 0,00 & 0,02 & 1,03 & 23,83 & هج.فردى12030 \\
\hline & & & & & & 0,00 & 1,01 & 23,86 & هج. تُلاتى324 \\
\hline & & & & & & & 0,00 & 24,86 & هج. نلانىى321 \\
\hline
\end{tabular}

المصدر: حسبت من بيانات وزارة الزر اعة واستصلاح الار اضى، قطاع الثئون الاقتصادية، نشرة الاقتصاد الزر اعى، اعداد متفرقة. أقل فرق معنوى L.S.D

جدول ( 7 ) نتائج تقير معنوية الفروق بين إنتاجية أهم أصناف الذرة الثامية المزروعة في مصر العليا خلال الفترة ( 2007 (2009 2009 )

\begin{tabular}{|c|c|c|c|c|c|c|c|c|c|}
\hline بلدي & فردى هُ 2كت & فردىهتج 203 & ثلاثى هُمجن & هجزفئ & وزجنيجني & ثلاثى هُج 32 & ثلاثى هُجْ 32 & & الصنف \\
\hline 21,44 & 23,84 & 24,22 & 24,29 & 24,38 & 25,13 & 25,18 & 25,27 & الآتنتاحسة ط & \\
\hline
\end{tabular}




\begin{tabular}{|c|c|c|c|c|c|c|c|c|c|}
\hline 0,00 & 2,40 & $* 2,79$ & $* 2,85$ & $* 2,94$ & $* 3,69$ & $* 3,74$ & $* 3,83$ & 21,44 & بلدي \\
\hline & 0,00 & 0,38 & 0,45 & 0,54 & 1,29 & 1,34 & 1,43 & 23,84 & هج.فردى20ك8 \\
\hline & & 0,00 & 0,07 & 0,15 & 0,90 & 0,96 & 1,04 & 24,22 & هج.فردى2030 \\
\hline & & & 0,00 & 0,09 & 0,84 & 0,89 & 0,98 & 24,29 & هج. ثلاثى310 \\
\hline & & & & 0,00 & 0,75 & 0,80 & 0,89 & 24,38 & هج.فردى 10 \\
\hline & & & & & 0,00 & 0,05 & 0,14 & 25,13 & هج.فرديوطنية4 \\
\hline & & & & & & 0,00 & 0,09 & 25,18 & هج. ثلاثى324 \\
\hline & & & & & & & 0,00 & 25,27 & هج. ثلاثى321 \\
\hline
\end{tabular}

المصدر: حسبت من بيانات وزارة الزر اعة واستصلاح الار اضى، قطاع الثئون الاقتصادية، نشرة الاقتصاد الزر اعى، اعداد متفرقة.

2.56 = L.S.D أقل فرق معنوى

جدول ( 8 ) نتائج تقدير معنوية الفروق بين إنتاجية أهم أصناف الذرة الثامية المزروعة خارج الوادي خلال الفترة ( 2007 ( 2009 )

\begin{tabular}{|c|c|c|c|c|c|c|c|c|c|}
\hline بلدي بلدي & وطنيةزدى & ثلاثى هج. & فردى هُج. & ثلاثى هُ3. & ثلاثى هُ 321 & هج.فردى 10 & فردى هُجنك8 & \multirow[t]{2}{*}{ منتوسطة } & \multirow[t]{2}{*}{ الصنف } \\
\hline 12,01 & 15,12 & 20,29 & 21,9 & 24,81 & 24,95 & 25,46 & 25,47 & & \\
\hline \multirow[t]{3}{*}{0,00} & $* 3,11$ & $* 8,28$ & $* 9,89$ & $* 12,80$ & $* 12,94$ & $* 13,45$ & $* 13,46$ & 12,01 & بلدي \\
\hline & 0,00 & $* 5,17$ & $* 6,78$ & $* 9,69$ & $* 9,83$ & $* 10,34$ & $* 10,35$ & 15,12 & هج.فرددوطنية4 \\
\hline & & 0,00 & 1,61 & $* 4,52$ & $* 4,66$ & $* 5,17$ & $* 5,18$ & 20,29 & هج. ثلاثى310 \\
\hline
\end{tabular}




\begin{tabular}{|c|c|c|c|c|c|c|c|c|c|}
\hline & & & & & & & & & \\
\hline & & & 0,00 & $* 2,91$ & $* 3,05$ & $* 3,56$ & $* 3,57$ & 21,9 & هج.فردى2030 \\
\hline & & & & 0,00 & 0,14 & 0,65 & 0,66 & 24,81 & هج. ثلاثى324 \\
\hline & & & & & 0,00 & 0,51 & 0,52 & 24,95 & هج. ثلاثى321 \\
\hline & & & & & & 0,00 & 0,01 & 25,46 & هج.فردى 10 \\
\hline & & & & & & & 0,00 & 25,47 & هج.فردى20ك8 \\
\hline
\end{tabular}

الدصدر: بيانات وزارة الزر اعة واستصلاح الاراضى، قطاع الثشئون الاقتصادية، نشرة الاقتصاد الزر اعى، اعداد متفرقة.

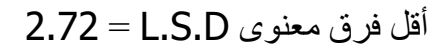

جدول ( 9 ) نتائج تقدير معنوية الفروق بين إنتاجية أهم أصناف الذرة الثامية المنزرعة على مستوى الجمهورية خلال الفترة ( 2007- 2009 )

\begin{tabular}{|c|c|c|c|c|c|c|c|c|c|}
\hline بلدي & ونج.فردى & ثلاثى هُج. & فردىهُج2030 & ثلاثى هج: & ثلاثى هُ32 & هج.فردى 10 & فردى هُجك & الإنتاجية ط مل & \\
\hline 20,66 & 23,42 & 23,82 & 23,93 & 25,38 & 25,48 & 25,73 & 25,81 & & \\
\hline \multirow[t]{5}{*}{0,00} & 2,76 & 3,16 & 3,28 & $* 4,72$ & $* 4,83$ & $* 5,07$ & $* 5,16$ & 20,66 & بلدي \\
\hline & 0,00 & 0,40 & 0,52 & 1,96 & 2,07 & 2,31 & 2,40 & 23,42 & هج.فردنوطنية4 \\
\hline & & 0,00 & 0,12 & 1,56 & 1,67 & 1,91 & 2,00 & 23,82 & هج. ثلاثى310 \\
\hline & & & 0,00 & 1,45 & 1,55 & 1,79 & 1,88 & 23,93 & هج.فردى2030 \\
\hline & & & & 0,00 & 0,10 & 0,35 & 0,43 & 25,38 & هج. ثلاثىى321 \\
\hline
\end{tabular}




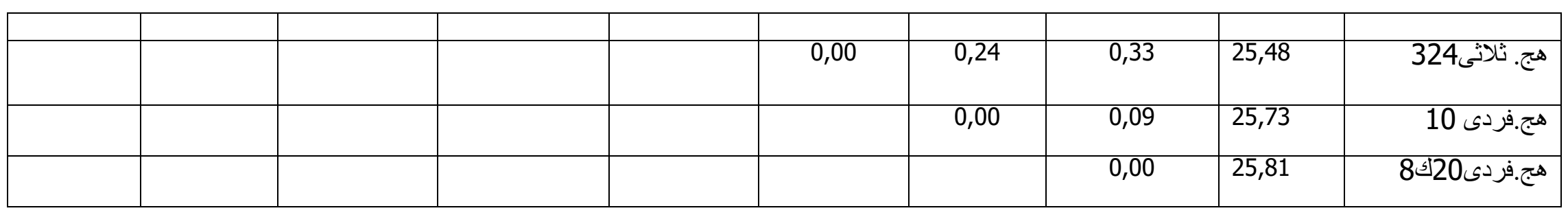

المصدر: حسبت من بيانات وز ارة الزر اعة واستصلاح الار اضى، قطاع الثئون الاقتصادية، نشرة الاقتصاد الزر اعى، أعداد متفرقة. 3.39 = L.S.D أقل فرق معنوى 
دور الأصناف المحنة في تحسين إنتاجية الذرة الثامية في مصر :

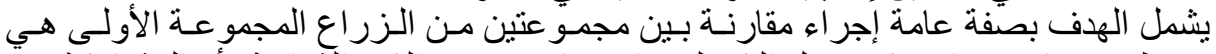

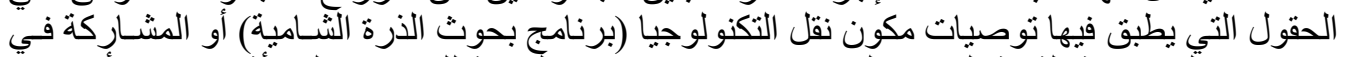

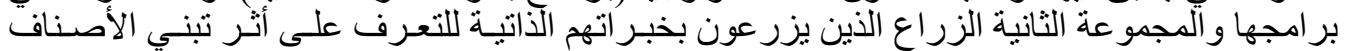

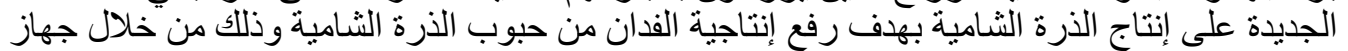

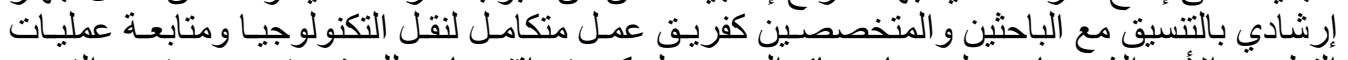

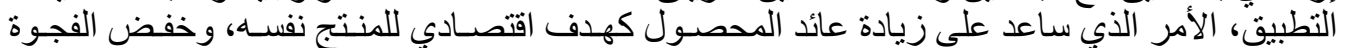

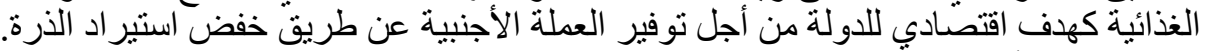

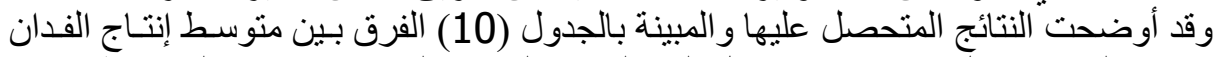

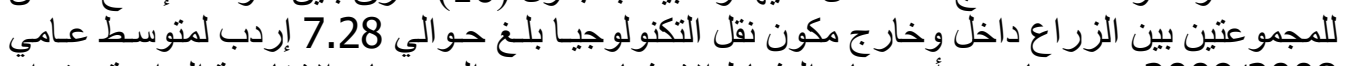

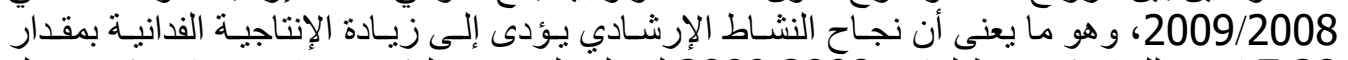

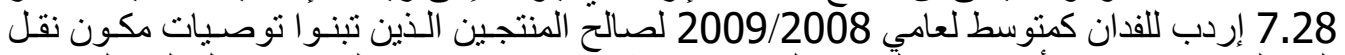

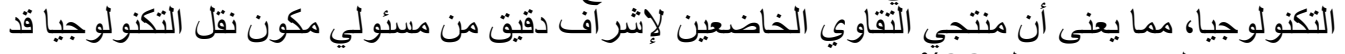

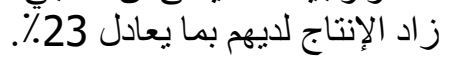

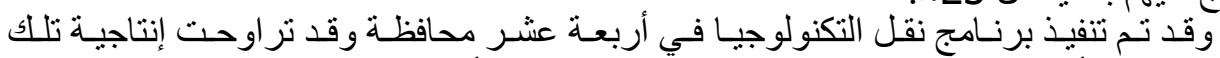

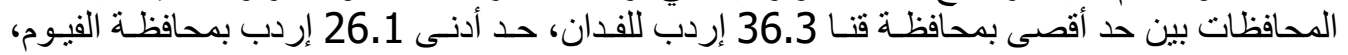

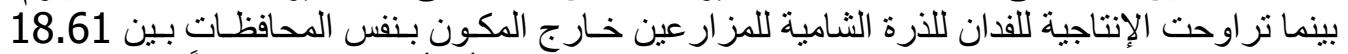

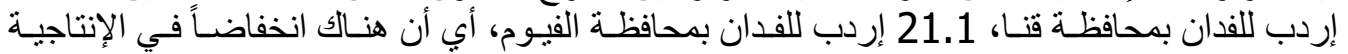

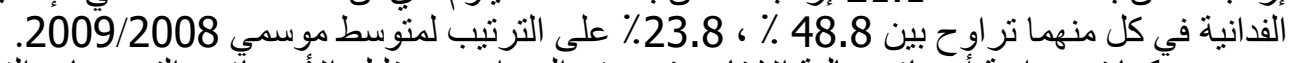

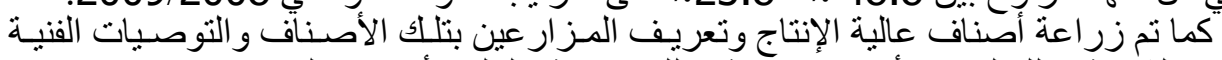

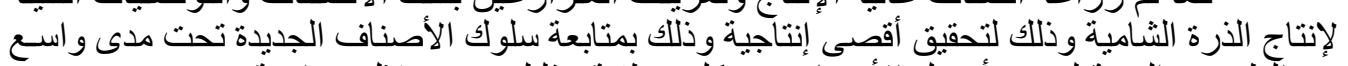

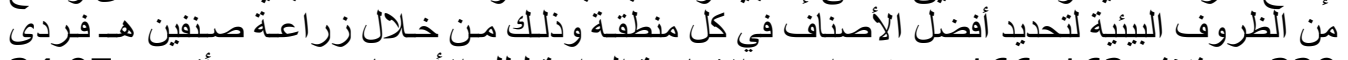

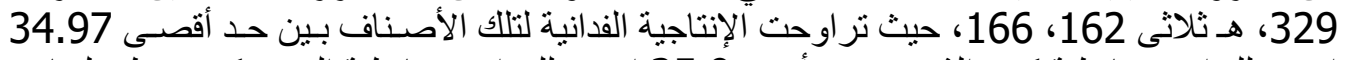

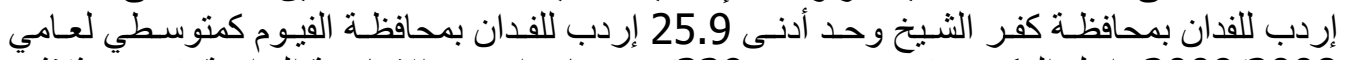

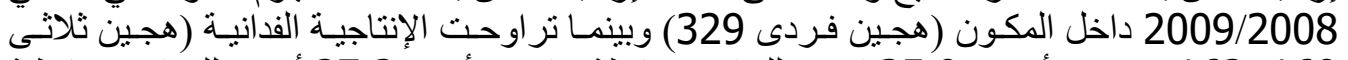

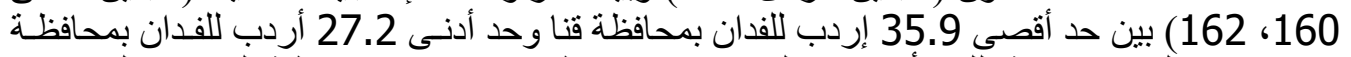

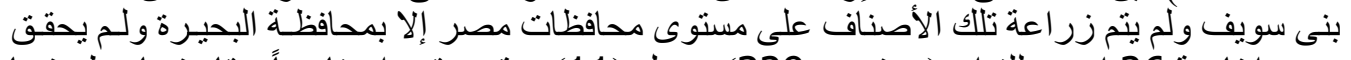

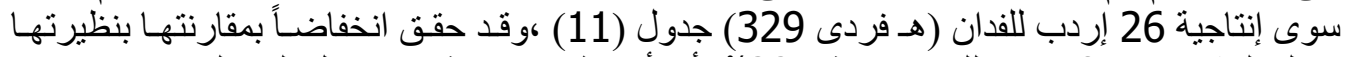

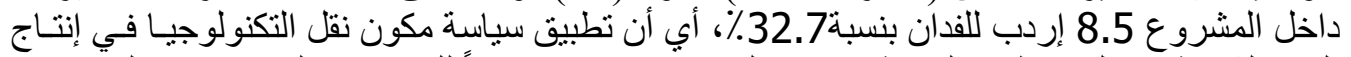

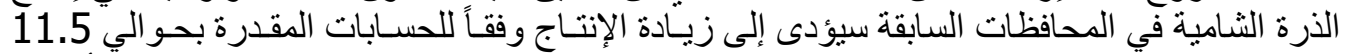

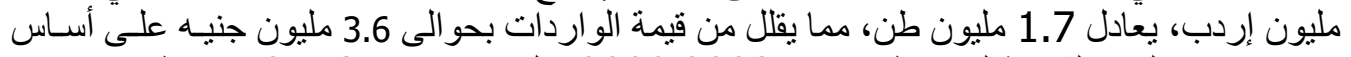

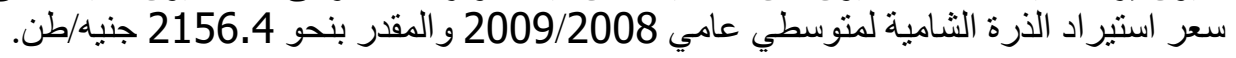


جدول (10) إنتاجية محصول الذرة الثامي لمتوسطي عامي 2009/2008 داخل وخارج

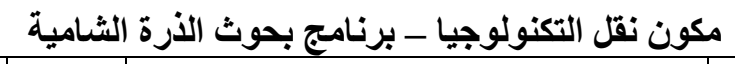

\begin{tabular}{|c|c|c|c|c|c|c|c|c|c|c|c|c|}
\hline \multirow[b]{2}{*}{ 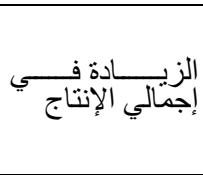 } & \multicolumn{3}{|c|}{ المساحة بالألف فدان } & \multirow{2}{*}{ خالزيـــــادل } & \multicolumn{3}{|c|}{ منوسطي عامي 2009/2008 } & \multicolumn{2}{|r|}{2009} & \multicolumn{2}{|r|}{2008} & \multirow[t]{2}{*}{ / السنوات } \\
\hline & 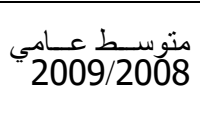 & 2009 & 2008 & & 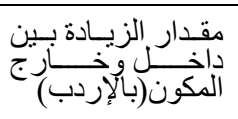 & الذكون & الماخكون & الذبكونبـارج) & المالخون & 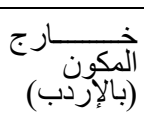 & 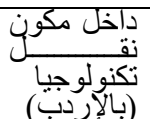 & \\
\hline 1422.7 & 195.7 & 210.4 & 181 & 27.1 & 7.27 & 26.79 & 34.06 & 26.7 & 33.88 & 26.87 & 34.52 & البحيرة \\
\hline 442.13 & 65.5 & 63.3 & 67.7 & 27.3 & 6.75 & 24.75 & 30.99 & 24.84 & 31.80 & 24.66 & 30.18 & الغربيه \\
\hline 563.8 & 53.9 & 53.7 & 54 & 42.3 & 10.46 & 24.72 & 35.18 & 24.72 & 35.48 & 24.71 & 34.87 & كفر الثُيخ \\
\hline 401.7 & 73.7 & 89.7 & 57.7 & 19.3 & 5.45 & 28.26 & 33.71 & 28.39 & 34.23 & 28.33 & 33.19 & الدفهليه \\
\hline 2015.8 & 218.4 & 234.6 & 22.1 & 39.3 & 9.23 & 23.5 & 32.73 & 23.3 & 31.99 & 23.68 & 33.46 & التُرقية \\
\hline 489.98 & 127.6 & 91.00 & 163.4 & 13.7 & 3.84 & 28.1 & 31.94 & 28.5 & 32.72 & 27.62 & 3.16 & المنوفيه \\
\hline 634.3 & 85.6 & 95.7 & 75.5 & 33.5 & 7.41 & 22.1 & 29.51 & 21.01 & 30.16 & 23.22 & 28.85 & القليو بيه \\
\hline 56.9 & 34.3 & 40.6 & 27.9 & 5.6 & 1.66 & 29.62 & 31.28 & 29.56 & 31.28 & 29.68 & - & 6 اكتوبر \\
\hline 886.6 & 161.2 & 151.2 & 171.1 & 24.4 & 5.65 & 22.5 & 28.00 & 22.82 & 26.90 & 22.09 & 29.1 & بني سويف \\
\hline 411.7 & 87.4 & 109.6 & 65.1 & 23.8 & 5.01 & 21.09 & 26.10 & 21.87 & 26.82 & 20.31 & 25.28 & الفيوم \\
\hline 1456.8 & 303.5 & 305.3 & 301.6 & 19.7 & 4.71 & 23.83 & 28.54 & 23.25 & 29.34 & 24.4 & 57.73 & المنيا \\
\hline 1236.9 & 134.3 & 137.3 & 131.3 & 38.2 & 9.21 & 24.1 & 33.31 & 24.62 & 34.28 & 23.55 & 32.33 & اسيوط \\
\hline 302.5 & 131.5 & 132.7 & 130.3 & 9.1 & 2.30 & 25.3 & 27.6 & 25.35 & 28.38 & 25.26 & 26.81 & سوهاج \\
\hline 936.9 & 52.9 & 51.00 & 54.7 & 48,8 & 17.71 & 18.61 & 36.32 & 18.57 & 36.473 & 18.65 & 33.78 & (i) \\
\hline 11.4606 .69 & 1448,4 & 1978.00 & 1073,9 & 23,2 & 7.3 & 24.2 & 31.48 & 24.07 & 31.48 & 24.26 & 3059 & المجموع \\
\hline
\end{tabular}

المصدر: وزارة الزراعة واستصلاح الاراضى، قطاع الثئون الاقتصادية، بيانات غير منشورة 
جدول رقم (11) نتائج الحملة القومية للنهوض بإنتاجية محصول الذرة الشامية عامي (2009-2008)

\begin{tabular}{|c|c|c|c|c|c|c|}
\hline \multicolumn{3}{|c|}{ هـ ـ. ف 166} & \multicolumn{3}{|c|}{ د هـ ث 329} & \multirow[t]{2}{*}{ البيان } \\
\hline المتوسط & 2009 & 2008 & المنوسط & 2009 & 2008 & \\
\hline 33.6 & 32.1 & 35.10 & 34.5 & 35.66 & 33.37 & البحيرة \\
\hline 31.2 & 32.64 & 29.82 & 30 & 30.66 & 29.39 & الغربية \\
\hline 35.4 & 35.56 & 35.19 & 34.97 & 35.40 & 34.54 & كفر الثيخ \\
\hline 35.8 & 36.03 & 35.58 & 31.61 & 32.43 & 30.79 & الدقلية \\
\hline 32.8 & 33.15 & 32.38 & 32.7 & 30.83 & 34.53 & الثرقية \\
\hline 32.7 & 33.48 & 31.85 & 31.2 & 31.96 & 30.46 & المنوفية \\
\hline 31.7 & 31.09 & 32.37 & 27.3 & 28.24 & 25.32 & القليو بية \\
\hline 28.8 & 27.00 & 30.59 & 27.2 & 26.80 & 27.61 & بني سويف \\
\hline 27.2 & 27.75 & 26.58 & 24.9 & 25.89 & 23.98 & الفيوم \\
\hline 30.1 & 29.48 & 30.70 & 28.98 & 29.20 & 28.76 & المنيا \\
\hline 34 & 34.82 & 33.20 & 31.1 & 32.75 & 31.45 & أسيوط \\
\hline 28.5 & 30.10 & 27.00 & 26.6 & 26.66 & 26.61 & سو هاج \\
\hline 35.9 & 38.10 & 33.71 & 34.1 & 34.30 & 33.84 & قتا \\
\hline 27.96 & 28.54 & 27.38 & 27.8 & 28.76 & 26.85 & النوبارية \\
\hline 30.96 & 32.07 & 29.85 & 30.4 & 30.89 & 29.85 & المجموع \\
\hline
\end{tabular}

المصدر: وزارة الزر اعة واستصلاح الأر اضي، قطاع الثئون الاقتصادية، بيانات غير منشورة

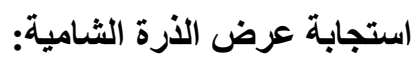

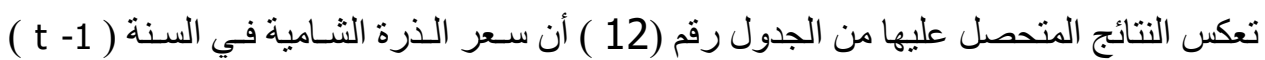

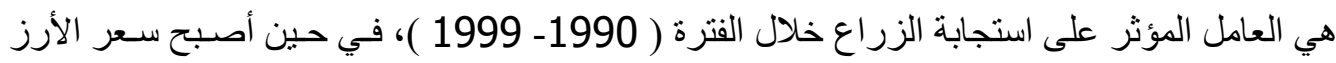

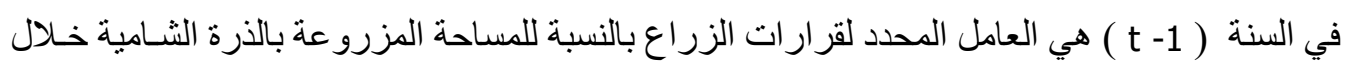

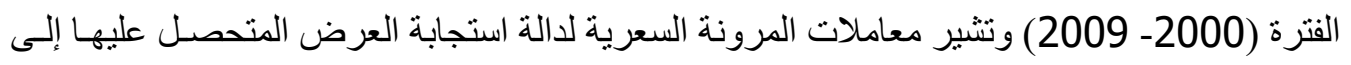

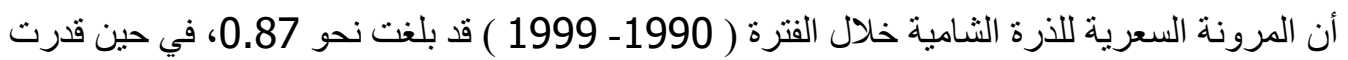

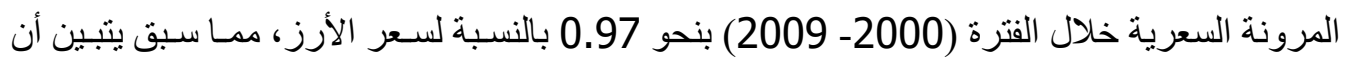

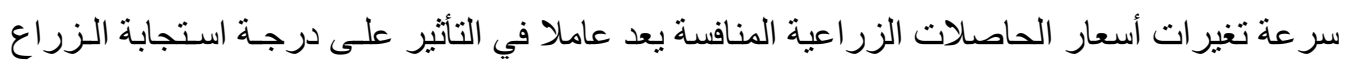

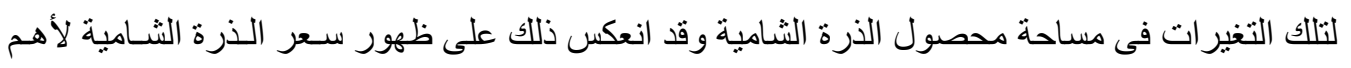

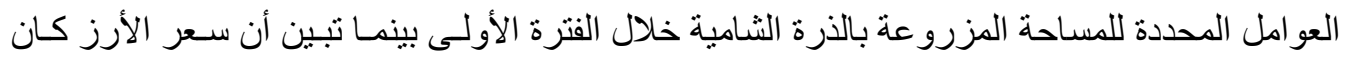


جدول رقم (12 ) معادلات استجابة العرض لمحصول الأرة الشامية في مصر

\begin{tabular}{|c|r|r|}
\hline$R^{2}$ & الفترة \\
\hline 0.73 & $Y_{1 t}=1204.9-67.52 X_{1 \mathrm{t}-1}$ & $1999-1990$ \\
& $(9.68)^{* *}$ & \\
\hline 0.75 & $Y_{21 t}=1425.3-1415.2 \times 2 \mathrm{t}-1$ & $2009-2000$ \\
& $(5.12)^{* *}$ & \\
\hline
\end{tabular}

المصدر: حسبت من بيانات وزارة الزر اعـة واستصـلاح الار اضـى، قطـاع الثــون الاقتصـادية، نشـرة الاقتصاد الزر اعي، أعداد متفرقة.

Y = القيمة التقديرية لمساحة الذرة الثامية بالألف فدان في السنة خلال الفترة 1990ـ 1999 Y Y2t X X1 t-1 X X السعر المزر عى لمحصول الأرز بالجنيه في السنة السابقة. 0.05 * معنوية عند مستوى

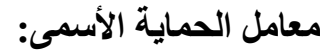

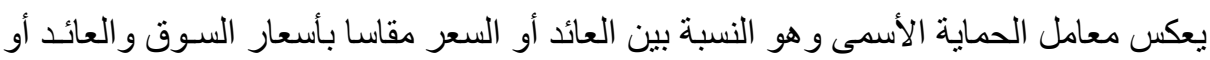

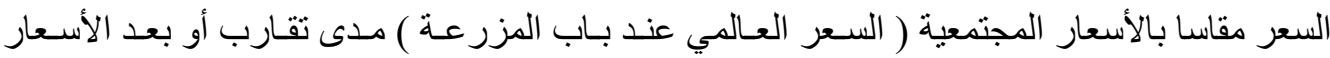

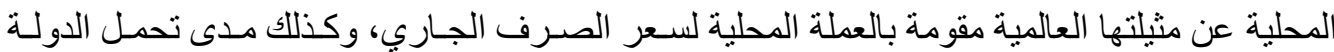

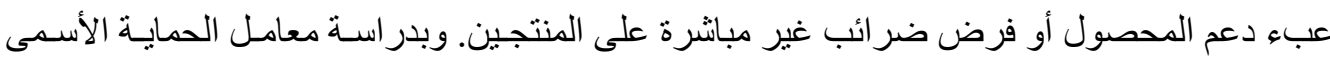

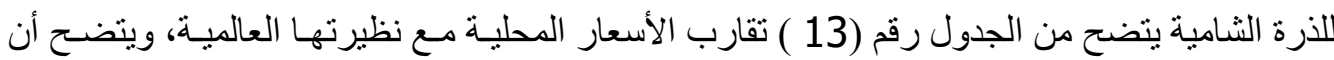

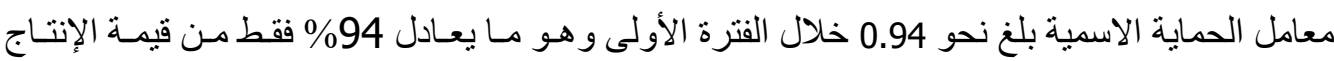

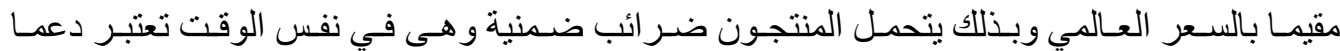
للمستهلكين يقدر بنحو 6\%، أما خلال الفترة الثانية فيشير نفس الجدول إلى ارتفاع السـعر المحلى عن الفـ

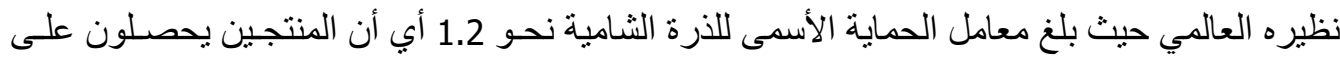
قيمة ناتجهم بالكامل بسعر أعلى من السعر العالمي مما يعنى أن هؤ لاء المنتجين لا يتحملون أي ضر ائب

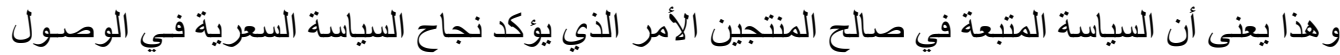

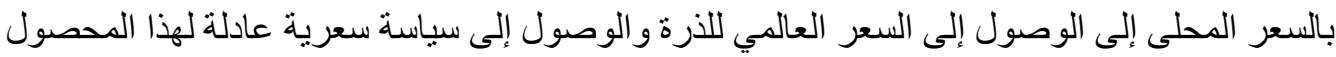

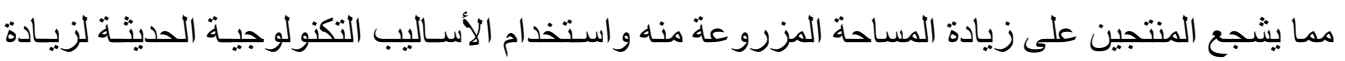
الإنتاج وبذلك تنخفض الكمية المستوردة من الذرة الثامية وبالتالي زيادة نسبة الاكتفاء الذاتي. 
جدول (13 ) معامل الحماية الأسمى لمحصول الذرة الثامية

\begin{tabular}{|c|c|c|}
\hline $2009-2007$ & $2006-2000$ & الفترة \\
\hline 1,19 & 0,94 & لزرة الثشامية \\
\hline
\end{tabular}

المصدر: حسبت من بيانات وز ارة الزر اعة واستصلاح الار اضى، قطاع الثئون الاقتصـادية، نشرة

الاقتصاد الزر اعي، أعداد منقرقة.

المراجع (المعار

1- لطفي هندي، الإحصاء التجريبي، دار المعارف بمصر ، 1971.

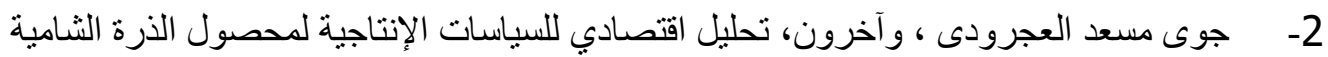

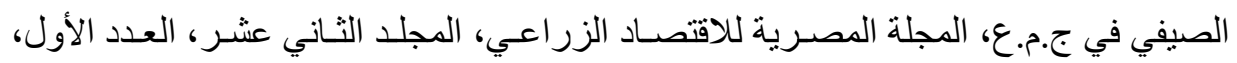

مارس 2002.

3- صلاح محمود مقلد ، وآخرون، در اسة اقتصـادية لأهم محاصيل الحبوب في ج.م.ع في ظل التل

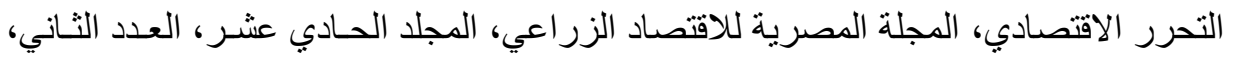

سبتمبر 2001.

4- وزارة الزر اعة واستصـلاح الار اضـى، مركز البحوث الزراعيـة، الإدارة المركزيـة للإرشـاد

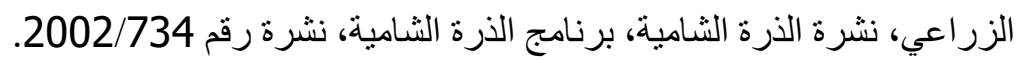

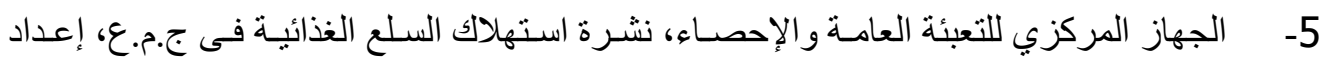

متفرقة.

6ـ الجهـاز المركزي للتعبئـة والإحصــاء، المركز القومي للمعلومـات، بيانـات التجـارة الخارجيـة،

سنوات مختلفة.

7 - وزارة الزر اعة و استصلاح الأرضي ـ قطاع الثئون الاقتصادية، نشرة الاقتصاد الزر اعي، أعداد

متفرقة.

المراجع

1- M.L. Jhingan, "Advanced Economic Theory", Konark Publication, M.L. Jhingan, 1998.

2- Robert B. Miller and Dean W. Wichern, Intermediate Business Statistical Analysis of variance, Regression, and Time series, Holt, Renehart and Winston, 1977.

3- Leonard J. Kazmier, Business Statistics, Series in Business, Mc Graw-Hill Book Company U.S.A, 1976.

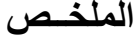

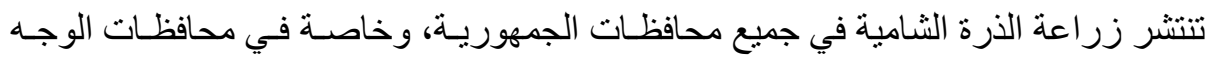

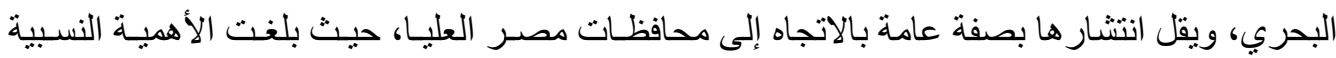




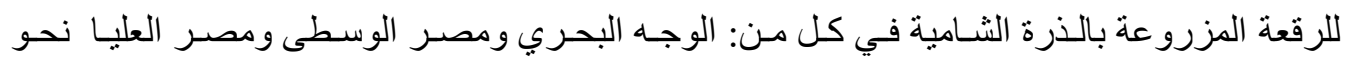

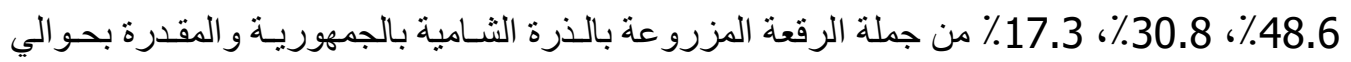

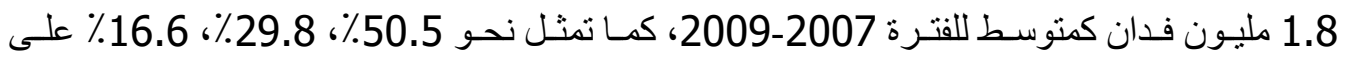
التو الي من كمية الناتج و المقدر بحو الي 6.2 مليون طن وذللك كمتوسط للفترة السابق ذكر ها. هذا وتجدر

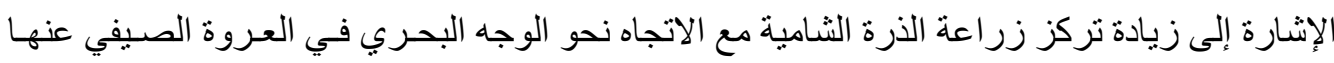

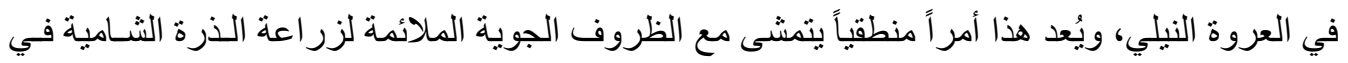
تللك العروات.

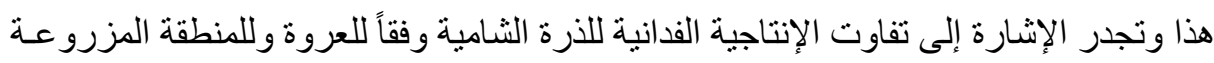

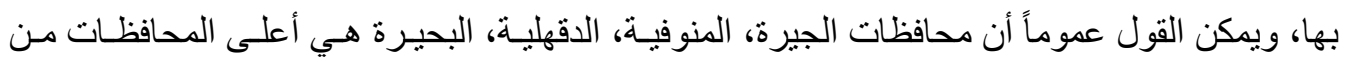

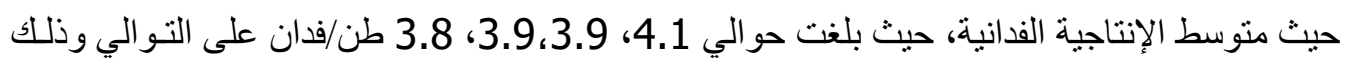
كمتوسط للفترة 2007-2009. من المعلوم أن كلا من التوسع الأفقي (في المساحة) والر أسي (في الإنتاجية) ذات أهمية كبرى

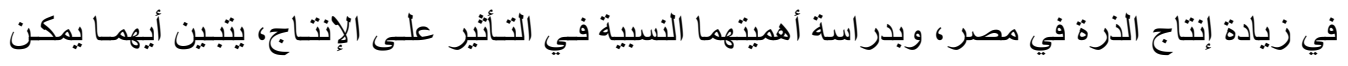

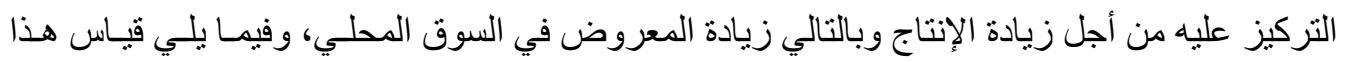

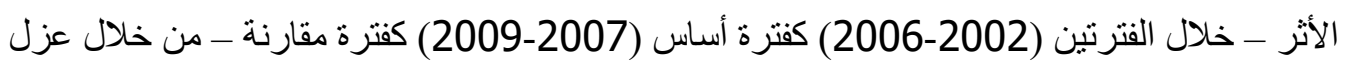
تأثير المساحة والإنتاجية على كمية الإنتاج.

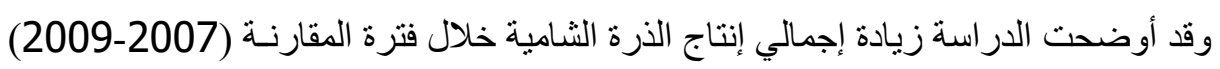

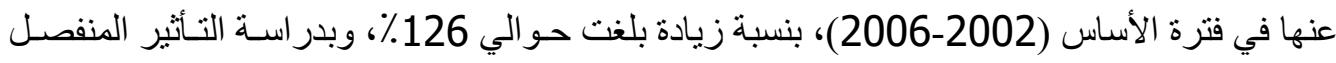

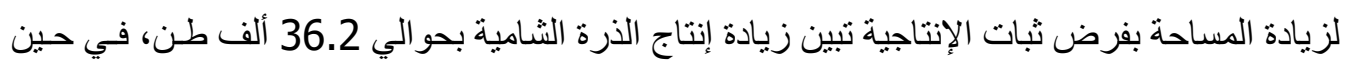

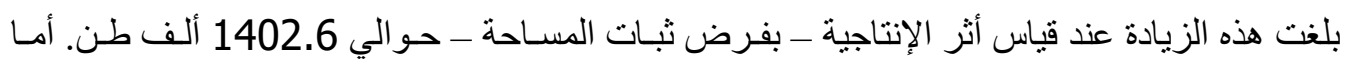

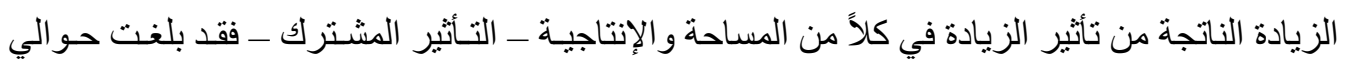
1439.1 ألف طن. هذا و عند تحديد الأهمية النسبية لتأثير كلا مـن المسـاحة والإنتاجيـة على إنتاج الذرة الثـامية

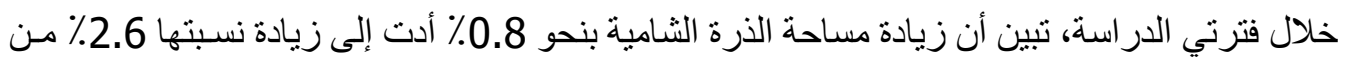

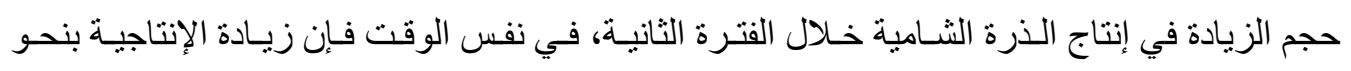

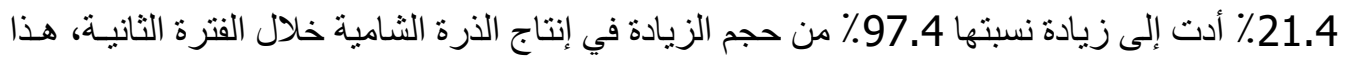

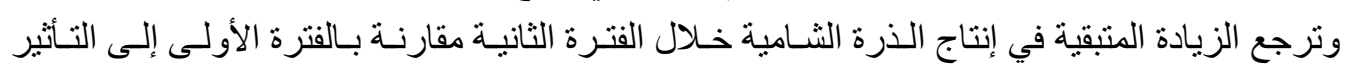

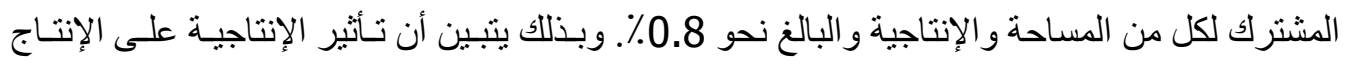

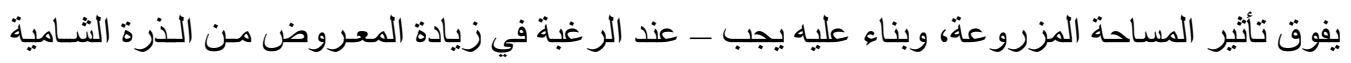

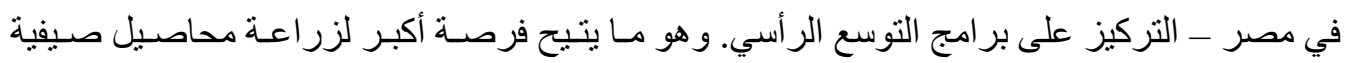

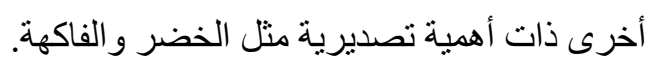

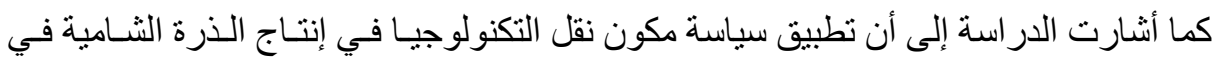

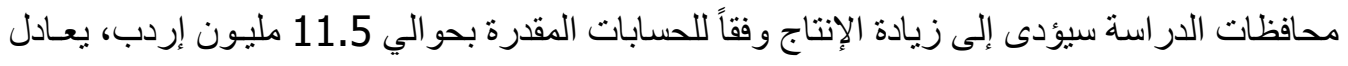

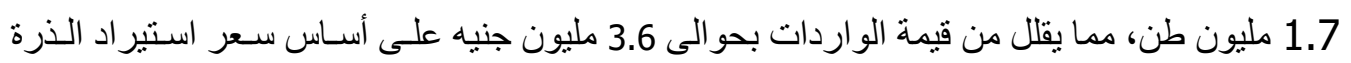

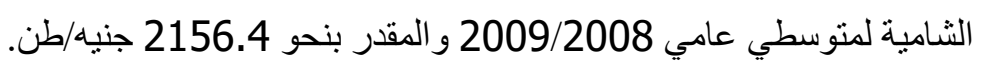
وبدراسة استجابة عرض الذرة الثامبة يتبين أن سرعة تغيرات أسعار الحاصلات الزر اعية

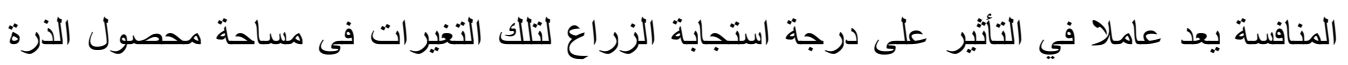


الثامية وقد انعكس ذلك على ظهور سعر الذرة الثامية لأهم العو امل المحددة للمساحة المزروعة بالذرة الثامية خلال الفترة ( 1990- 1999 )، بينما تبين أن سعر الأرز كان العامل المحدد لتلك الاستجابة خلال الفترة (2000- 2009).

\section{التوصيات}

$$
\text { توصى الدر اسة: }
$$

1- التنسيق بين المر اكز البحثيـة و الأجهزة الإرشـادية لمســاعدة المـزارعين على تبنـى الحزم

التكنولوجية بزر اعة محصول الذرة الثامية بما بضمن تحقيق إنتاجية فدانية عالية.

2- إعادة التوزيع الصنفى على مستوى المحافظات بما يحقى أعلى إنتاجيه. 


\title{
IMPACT OF RE-DISTRIBUTION OF CULTIVATED MAIZE VARIETIES ON ITS IMPORTS
}

\section{ALAA ELDIN SAID ELSHABRAWY}

Agricultural Economics Research Institute, ARC, Dokki, Giza

(Manuscript received 14 September 2011)

\begin{abstract}
Maize cultivate in all governorates of Egypt, especially in Lower Egypt, Maize area in general decreases as we move from north to south governorates. Average maize area during 2007- 2009, was about 1.8 million faddan, of which $48.6 \%, 30.8 \%$, and $17.3 \%$ cultivated in lower, middle, and upper Egypt respectively. Production of such area (6.2 million tons) is distributed among the above three regions as $50.5 \%$, $29.8 \%$, and $16.6 \%$, respectively. There is a difference between varieties productivity of maize at the same zone.

The study aims to determine the economic impact of the contribution of improved varieties to increase maize production, through study the current situation of maize production and shed light of the most important factors affecting the production, the study of varieties structure according to productivity, the production volume and areas of the maize.

The study indicate to increase the total maize production during the period (2007-2009) comparing by the base period (2002-2006), by about $126 \%$. Increasing in the maize area contributed by about 36.2 thousand tons, by supposing productivity stability. While the productivity - assuming the area stability contributed by about 1402.6 thousand tons. The impact of increasing in both area and productivity contributed by about 1439.1 thousand tons. The study shows that the relative impact of both area and productivity on the maize production during the two periods, it was found that increasing the maize area by $0.8 \%$ led to increasing by about $2.6 \%$ of the maize production during the second period, at the same time, increasing of productivity by $21.4 \%$ led to increasing by about $97.4 \%$ of the maize production during the same period, it means that the productivity impact on the production is greater than the impact of the cultivated area. So it should be focus on vertical expansion programs to increase the maize supply in Egypt.

The study also shows that the re-distribution of the improved varieties will lead to increase the maize production by about 11.5 million ardebs, reduces the value of maize imports by about 3.6 million pounds, since the import maize price estimated by about 2156.4 pounds / ton in the $2008 / 2009$.

The study of the maize supply response shows that the price of maize is the important factor on maize area during the period (1990 - 1999), while the price of rice is the important factor of this response during the period (2000-2009).
\end{abstract}

